\title{
Metodologia Trabalho De Projeto No Ensino De Testes De Hipóteses: Uma Análise Da Idoneidade Didática
}

\author{
Project Work Methodology In Teaching Hypothesis Testing: \\ An Analysis Of Didactic Suitability
}

\author{
Gabriela Gonçalves* \\ Instituto Superior de Engenharia do Porto - (ISEP) \\ José António Fernandes ** \\ Universidade do Minho - (UM)
}

\begin{abstract}
Resumo
Neste trabalho analisamos a idoneidade didática de uma intervenção de ensino sobre a aprendizagem de testes de hipóteses, baseada numa metodologia de trabalho de projeto, que foi implementada em 31 estudantes da Licenciatura de Engenharia Informática do Instituto Superior de Engenharia do Porto, no ano letivo 2014-2015. Nessa intervenção de ensino, os estudantes organizaram-se em sete grupos e realizaram um trabalho de projeto, em que os vários dados produzidos pelos diferentes grupos foram estudados e discutidos segundo os componentes e indicadores da idoneidade epistémica, cognitiva e mediacional. A partir da análise produzida, em conclusão, verificou-se uma alta idoneidade epistémica e médias idoneidades cognitiva e mediacional.
\end{abstract}

Palavras-chave: Idoneidade didática, Testes de hipóteses, Trabalho de projeto, Alunos do ensino superior

\begin{abstract}
In this paper we analyse the didactic suitability of a teaching intervention on the learning of hypothesis tests, based on a project work methodology, which was implemented in 31 students of the Bachelor of Computer Informatics Engineering of the School of Engineering of Porto, in the academic year 2014 2015. In this teaching intervention the students, organized into seven groups, carried out a project work, in which the various data produced by the different groups were studied and discussed according to the components and indicators of epistemic, cognitive and mediational suitability. From the analysis produced, in conclusion, there was a high epistemic suitability and a medium cognitive and mediational suitability.
\end{abstract}

Keywords: Didactic suitability, Hypothesis testing, Project work, Higher education students

\footnotetext{
* Doutora em Ciências da Educação, especialidade de Educação Matemática pela Universidade do Minho (UM). Professora Adjunta no Instituto Superior de Engenharia do Porto (ISEP), Porto, Portugal. E-mail: gmc@isep.ipp.pt.

* * Doutor em Educação, Área de conhecimento de Metodologia do Ensino da Matemática pela Universidade do Minho (UM), Portugal. Professor Associado no Instituto de Educação da Universidade do Minho (UM), Braga, Portugal. E-mail: jfernandes@ie.uminho.pt.
} 


\section{Introdução}

Nos dias de hoje, a Estatística é uma ferramenta indispensável para qualquer pessoa que necessita de analisar dados tendo em vista a tomada de decisões, seja no seu trabalho ou na sua vida pessoal. A rapidez e a agilidade no processo de obtenção de informação a partir dos dados são fatores muito valorizados atualmente, para os quais muito tem contribuído o avanço tecnológico através do uso de computadores que processam uma imensa quantidade de dados num "piscar de olhos".

O ensino da Estatística no ensino superior, nas diversas áreas, poderá ser apresentado aos alunos como uma ferramenta de análise de dados, para que eles tomem conhecimento dos seus métodos, apreciem o seu interesse e tomem consciência da necessidade de usá-la nos trabalhos científicos que envolvam a análise de dados. O aluno deverá perceber a importância do conhecimento das ferramentas básicas de organização e análise de dados para o exercício da sua futura atividade profissional.

Nos cursos de Engenharia, por serem da área das ciências aplicadas, a unidade curricular de Estatística pode ter um desenvolvimento maior, pois estes alunos têm uma boa formação em matemática. Apesar destes alunos terem uma boa base de matemática, Ara e Musetti (2001) notam que o ensino da Estatística a partir da fundamentação matemática dos conceitos envolvidos não tem despertado o interesse esperado nos alunos. Os investigadores acham que essa falta de interesse pela unidade curricular se deve, entre outros fatores, ao facto de que a Estatística estuda fenómenos aleatórios, com os quais o aluno do curso de engenharia, em geral, não está familiarizado. Um engenheiro está mais habituado a analisar aspetos determinísticos dos fenómenos, o que dificulta inclusive a sua compreensão da função desempenhada pela Estatística na análise desses fenómenos. Fischbein (1975) atribui à prevalência da visão determinística do mundo a origem das dificuldades dos estudantes em estocástica.

No caso dos testes de hipóteses, tema aqui explorado, segundo Batanero (2001), apesar de se tratar de um campo de aplicação específico, são a área da inferência estatística provavelmente menos compreendida e a mais confundida. A este propósito, também Gonçalves, Fernandes e Nascimento (2014) referem a necessidade de rever a forma de ensino da inferência estatística, e mais concretamente na interpretação do problema, na formulação das hipóteses estatísticas e na compreensão do nível de significância. Alguns dos erros relativos a essas fases do processo de inferência podem provocar dificuldades na resolução dos problemas de testes de hipóteses. Além disso, os autores salientam que os alunos mostram ter muita 
dificuldade na justificação da forma como pensam em Estatística, isto é, a forma como explicitam o seu raciocínio estatístico (Gonçalves, Fernandes \& Nascimento, 2015).

No ensino da Estatística, o trabalho de projeto constitui uma metodologia especialmente favorável ao desenvolvimento de competências de trabalho de grupo, à promoção de uma abordagem realista da Estatística (Fernandes, Carvalho \& Ribeiro, 2007) e à utilização de tecnologia (Fernandes, Júnior \& Vasconcelos, 2013). No caso do trabalho de grupo, Petocz e Reid (2007) identificaram vários aspetos positivos, designadamente, ao permitir aos estudantes explorar tarefas mais compreensivas, expor os estudantes aos diferentes pontos de vista dos outros membros do grupo e encorajar os alunos a prepararem-se para o ponto de vista real (que cada vez mais envolve trabalho em equipa); ao capacitar os alunos a adquirir um insight sobre as dinâmicas e os processos de grupo e o desenvolvimento de competências interpessoais; e ao favorecer a reflexão e a discussão como parte essencial do processo de se tornarem práticos competentes e reflexivos.

Neste trabalho, apresentamos os resultados obtidos no âmbito de uma metodologia de ensino, focada no trabalho de projeto, recorrendo a diferentes indicadores de idoneidade didática do Enfoque Ontossemiótico do conhecimento e do ensino da matemática (EOS), desenvolvido por Godino e colaboradores (e.g., Godino, 2011; Godino, 2013; Godino, Batanero $\&$ Fonte, 2007), com o objetivo de averiguar se a metodologia de ensino implementada contribuiu para uma melhor aprendizagem dos alunos em testes de hipóteses.

\section{Referencial Teórico}

No presente estudo recorremos aos indicadores de idoneidade didática como ferramenta de análise pois, como destaca Godino (2011), a noção de idoneidade didática pode ser utilizada na análise de um processo de estudo implementado e também pode ser útil para analisar aspetos parciais de um processo de estudo, como sejam materiais didáticos, respostas dos alunos a uma tarefa específica e acontecimentos didáticos pontuais. De seguida, iremos referir-nos às diferentes dimensões de idoneidade didática.

A idoneidade didática de um processo de instrução matemática define-se como a articulação coerente e sistémica das seguintes dimensões (Godino, Contreras \& Font, 2006):

- Idoneidade epistémica: refere-se ao grau de representatividade dos significados institucionais implementados ou pretendidos, com relação ao significado de referência; 
- Idoneidade cognitiva: expresso pelo grau em que os significados pretendidos/implementados se situem na zona de desenvolvimento potencial dos alunos, assim como a proximidade destes significados pretendidos com os implementados;

- Idoneidade interacional: um processo de ensino e aprendizagem terá maior adequação, desde o ponto de vista interacional, se as configurações e trajetórias didáticas permitirem, por uma parte, identificar conflitos semióticos potenciais (que podem ser detetados a priori) e, por outra parte, resolver os conflitos que forem experimentados durante o processo de instrução;

- Idoneidade mediacional: grau de disponibilidade e apropriação dos recursos materiais e temporais necessários para o desenvolvimento do processo de ensino e aprendizagem;

- Idoneidade emocional: grau de implicação (interesse, motivação, ...) do aluno no processo de estudo. A idoneidade emocional está relacionada com fatores que dependem tanto da instituição quanto do aluno e da sua história escolar prévia;

- Idoneidade ecológica: grau em que o processo de estudo se ajusta ao projeto educativo, à escola, à sociedade e aos condicionamentos do contexto no qual se desenvolve.

Estas adequabilidades/idoneidades devem ser integradas tendo em conta as interações entre as mesmas, o que requer abordar a adequação didática como um critério sistémico de apropriação e pertinência com relação ao projeto educativo global (Godino, Wilhelmi \& Bencomo, 2005). Esta adequação deve ser interpretada como relativa às circunstâncias temporais e contextuais, o que requer uma atitude de reflexão e investigação por parte do professor e demais agentes que compartilham a responsabilidade do projeto educativo.

Consideramos úteis as noções, antes referidas, para a análise de projetos e experiências de ensino. Os distintos elementos podem interagir entre si, o que sugere a extraordinária complexidade dos processos de ensino e aprendizagem. Atingir uma alta adequação numa das dimensões, por exemplo, a epistémica, pode requerer capacidades cognitivas para as quais está direcionado o ensino e que os estudantes não possuem. Uma vez obtido um certo equilíbrio entre as dimensões epistémica e cognitiva, é necessário que a trajetória didática otimize a identificação e solução de conflitos semióticos. Os recursos técnicos e o tempo disponível também interatuam com as situações-problema, a linguagem, etc.

$\mathrm{Na}$ Figura 1 resumimos as dimensões que compõem a adequação didática, representando mediante um hexágono regular a adequação correspondente a um processo de estudo pretendido ou programado, no qual, a priori, se supõe um grau máximo das adequações 
parciais. O hexágono irregular inscrito corresponde às adequações efetivamente atingidas na realização de um processo de estudo implementado.

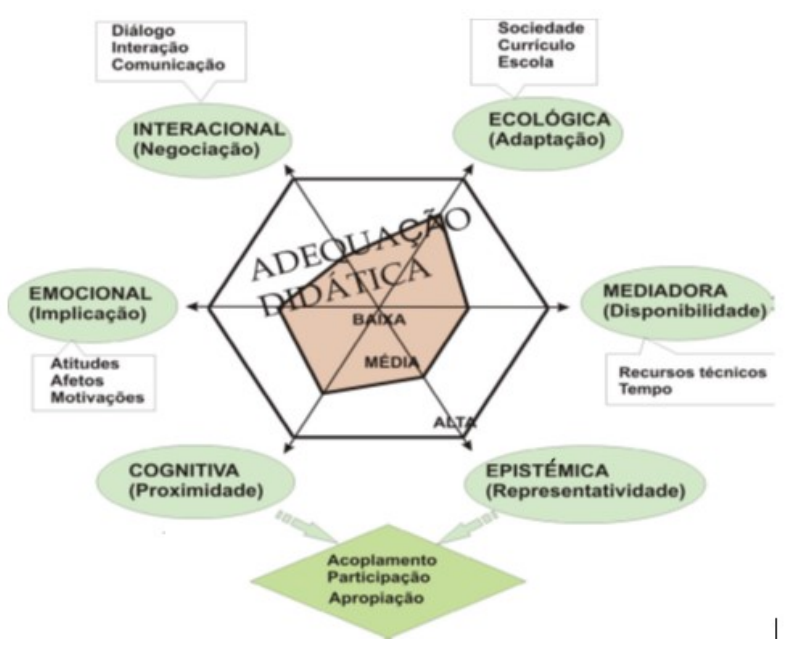

Figura 1: Dimensões da idoneidade didática Fonte: Godino, Batanero \& Font (2008, p. 24)

As ferramentas descritas podem ser aplicadas à análise de um processo pontual de estudo implementado numa aula, ao planeamento ou ao desenvolvimento de uma unidade didática ou a um nível global, como pode ser o desenvolvimento de um curso ou uma proposta curricular. Também podem ser úteis para analisar aspetos parciais de um processo de estudo, como seja um material didático, um livro de texto, respostas dos estudantes a tarefas específicas ou "incidentes didáticos" pontuais.

Com o estudo da adequação/idoneidade didática pretendemos, fundamentalmente, analisar os processos de instrução implementados num método de ensino, tendo em vista a promoção da aprendizagem dos estudantes sobre testes de hipóteses.

\section{Metodologia}

Neste texto vamos analisar a metodologia de ensino, focada no trabalho de projeto, recorrendo às dimensões de idoneidade epistémica, idoneidade cognitiva e idoneidade mediacional, considerando em cada uma delas vários componentes e indicadores. Estes componentes e indicadores são apresentados na próxima secção de análise de dados.

A amostra, constituída por 31 alunos, foi selecionada entre os alunos da Licenciatura de Engenharia Informática do Instituto Superior de Engenharia do Porto, no ano letivo de 201415, que se encontravam a frequentar a unidade curricular (UC) de Matemática Computacional. Dos 31 alunos, 25 eram do sexo masculino e seis do sexo feminino e todos os alunos se encontravam a frequentar esta UC pela primeira vez. Previamente à realização dos projetos, foi 
feita uma apresentação teórica do tema Testes de Hipóteses (TH) durante duas horas, enquanto o projeto se desenvolveu ao longo de quatro aulas teórico-práticas, com um tempo presencial de seis horas e um tempo tutorial de quatro horas.

No âmbito do tema TH, os alunos, organizados em sete pequenos grupos (com 4 ou 5 estudantes), realizaram um trabalho de projeto sobre a aplicação de testes de hipóteses. Para tal, os alunos, com a supervisão da professora, elaboraram um questionário sobre as Redes Sociais, constituído por 18 questões fechadas, aplicaram-no aos alunos e organizaram um ficheiro no software R a partir dos dados obtidos, o qual foi disponibilizado aos grupos. Assim, a temática dos projetos foi a das Redes Sociais e, para a sua realização, os alunos tiveram de percorrer o seguinte plano, apresentado pela professora: estabelecer o seu objetivo; escolher, pelo menos, quatro questões do questionário, de forma a poderem aplicar pelo menos dois dos testes de hipóteses (TH) lecionados; usar o software R na aplicação dos TH; caraterizar resumidamente a amostra; e seguir as indicações dadas sobre como deveriam apresentar o relatório final.

Na realização dos trabalhos de projeto os alunos deveriam produzir um relatório escrito sobre o trabalho efetuado, incluindo as seguintes secções sugeridas pela professora: título do trabalho; objetivo; resumo; introdução; descrição dos dados usados no estudo; análise e tratamento de dados; conclusões e discussão; e bibliografia. Terminada a realização do trabalho de projeto, os alunos efetuaram uma breve apresentação do seu trabalho para a turma, dispondo para tal de um tempo de 10 minutos.

Também ao longo da realização do trabalho de projeto, no final da realização de cada uma das quatro fases desse trabalho (Objetivos/Questões de investigação, Descrição dos dados usados no estudo, Análise e tratamento de dados e Conclusão e discussão), os alunos responderam a um breve questionário de autoavaliação contemplando quatro questões: na primeira questionavam-se os alunos sobre se consideravam ter atingido o que se pretendia com a respetiva fase do projeto; na segunda e terceira questionavam-se sobre os aspetos em que se sentiram mais capazes e em que sentiram mais dificuldade, respetivamente; e, por fim, solicitavam-se sugestões para a melhoria do trabalho de projeto.

Após a realização e apresentação do trabalho de projeto, solicitou-se aos alunos que respondessem a um questionário tendo em vista obter as suas perceções sobre a metodologia de trabalho de projeto.

A partir dos trabalhos elaborados pelos alunos, centraremos a nossa análise principalmente em três das seis dimensões da idoneidade didática, isto é, as dimensões epistémica, cognitiva e mediacional. 


\section{Análise De Resultados}

Nesta secção apresentam-se os principais resultados obtidos em cada uma das três dimensões de idoneidade estudadas nas fases a priori e a posteriori, considerando em cada uma delas os componentes e indicadores que as caracterizam.

\subsection{Análise Da Idoneidade Epistémica}

Tal como nas outras dimensões, a análise da idoneidade epistémica vai ser realizada a priori e a posteriori, seguindo os componentes e indicadores epistémicos referenciados no EOS (Godino, 2013, p. 116), que são apresentados na Quadro 1.

Quadro 1 - Componentes e indicadores da idoneidade epistémica

\begin{tabular}{|c|c|}
\hline Componentes & Indicadores (referência/uso) \\
\hline Situações-problema & $\begin{array}{l}\text { - Apresenta-se uma amostra representativa e articulada de situações } \\
\text { de contextualização, exercitação e aplicação. } \\
\text { - Propõem-se situações de formulação de problemas } \\
\text { (problematização). }\end{array}$ \\
\hline Linguagem & $\begin{array}{l}\text { - Uso de diferentes modos de expressão matemática (verbal, gráfica, } \\
\text { simbólica), tradução e conversão entre as mesmas. } \\
\text { - Nível de linguagem adequado aos estudantes. } \\
\text { - Propõem-se situações de expressão matemática e interpretação. }\end{array}$ \\
\hline $\begin{array}{l}\text { Regras (definições, } \\
\text { proposições, procedimentos) }\end{array}$ & $\begin{array}{l}\text { - As definições e procedimentos são claros e corretos e estão } \\
\text { adaptados ao nível educativo a que se dirigem. } \\
\text { - Apresentam-se enunciados e procedimentos fundamentais do tema } \\
\text { para o nível educativo dado. } \\
\text { - Propõem-se situações onde os estudantes tenham que criar ou } \\
\text { negociar definições, proposições ou procedimentos. }\end{array}$ \\
\hline Argumentos & $\begin{array}{l}\text { - As explicações, comprovações e demonstrações são adequadas ao } \\
\text { nível educativo a que se dirigem. } \\
\text { - Promovem-se situações onde os alunos tenham que argumentar. }\end{array}$ \\
\hline Relações & $\begin{array}{l}\text { - Os objetos matemáticos (problemas, definições, proposições) } \\
\text { relacionam-se e conectam-se entre si. } \\
\text { - Identificam-se e articulam-se os diversos significados dos objetos } \\
\text { que intervêm nas práticas matemáticas. }\end{array}$ \\
\hline
\end{tabular}

Fonte: Godino, 2013, p. 119 


\subsubsection{Análise A Priori}

\section{Situações-problema}

S1) Que tipo de situações-problema específicas permite formular o enunciado do trabalho?

A partir do questionário Redes Sociais (RS), cada grupo escolhe quatro questões de investigação, como por exemplo: "Possuis um Tablet para aceder as redes sociais?"

S2) Que variáveis permitem generalizar a atividade matemática e em que direção?

Com as questões escolhidas caracteriza-se a amostra e indicam-se os TH que se podem aplicar. Por exemplo, para a questão "Possuis um Tablet para aceder as redes sociais?", caracteriza-se a amostra em função do género e aplica-se um TH para a proporção para determinar se a proporção de rapazes que acede à internet, através de um Tablet, é maior do que a proporção de raparigas.

Pretende-se que os alunos percebam, para as questões escolhidas, como caracterizar a amostra e que TH seriam mais adequados utilizar.

\section{Linguagem}

L1) Introduz-se uma linguagem específica? Que novos termos, expressões, símbolos e gráficos se introduzem?

Palavras com significado matemático: hipótese nula e alternativa, TH, nível de significância, valor de prova, intervalo de confiança, tomada de decisão.

Representação gráfica da amostra: gráfico de barras, histograma e tabelas de frequência. Formulação das hipóteses nula e alternativa.

L2) Que conhecimentos linguísticos prévios requer o uso do software R?

Supõem-se previamente adquiridos conhecimentos básicos de Estatística.

Supõem-se conhecidas as linguagens dos $\mathrm{TH}\left(H_{0}, H_{1}, \ldots\right)$ e das representações gráficas: gráficos de barras, histogramas e tabelas de frequência.

A escolha do TH em função das variáveis a tratar, a interpretação do resultado dos TH e das representações gráficas. $\mathrm{R}$.

Não é necessário conhecer nenhuma linguagem de programação para utilizar o software

L3) É útil na progressão da aprendizagem estatística a linguagem específica introduzida? 
Dada a utilização cada vez mais generalizada de recursos computacionais (softwares estatísticos), as convenções linguísticas utilizadas podem aparecer noutros softwares similares.

\section{Regras (definições, proposições, procedimentos)}

R1) Que técnicas específicas são necessárias para a resolução do trabalho proposto?

Manipulação do software R para a obtenção das representações gráficas, TH e tabelas de contingência para a sua realização.

R2) Que técnicas prévias são necessárias para dominar e aplicar novas técnicas?

Manipulação e execução de programas informáticos.

Conhecimentos de estatística descritiva.

R3) Que conceitos específicos se preveem que surjam das práticas matemáticas implementadas?

Representações gráficas em função das varáveis escolhidas.

TH adequados às questões escolhidas.

R4) Que conceitos prévios, que se supõem conhecidos, se usam de forma explícita ou implícita?

Representações gráficas: variável; amostra; gráfico de barras; histograma; tabela de frequências; intervalo de confiança (IC); TH; hipótese nula e alternativa; estatística do teste; nível de significância; região crítica; valor de prova.

\section{Argumentos (justificações ou argumentações)}

A1) Que tipo de justificações são necessárias para a resolução das representações gráficas e dos TH usando o software R?

Justificação da caracterização da amostra tendo por base a representação gráfica ou as tabelas de frequência.

Justificação do TH a utilizar para cada questão.

Justificação (conclusão) dos resultados obtidos na resolução dos TH.

\section{Relações}

R1) As justificações específicas para os resultados obtidos através do software R apoiam-se noutras anteriores?

As justificações podem, eventualmente, apoiar-se nas justificações das representações gráficas e das tabelas de frequência.

A justificação dos resultados obtidos nos TH pode ser relacionada com o intervalo de confiança obtido e com o valor de prova. 
R2) Em que situações se pode generalizar as justificações proporcionadas pelos resultados na aplicação dos $\mathrm{TH}$ ?

Como foi pedido aos alunos que caracterizassem a amostra em função do género, do estado civil e da idade com que começaram a aceder às RS, com essa informação e com os TH aplicados a questões que usassem essas variáveis poderiam tirar ilações, como por exemplo: "Quem acede mais às RS, são os homens ou as mulheres?"

Relacionar e identificar o TH com a formulação das hipóteses.

Relacionar as representações da formulação das hipóteses com a tomada de decisão.

\subsubsection{Análise A Posteriori}

\section{Situações-problema}

Analisando os sete projetos, podemos concluir que seis apresentaram as suas quatro questões de investigação, a forma como iam caracterizar a amostra e que TH deviam aplicar para cada uma das questões escolhidas. Apenas um não mencionou que iria caracterizar a amostra em função dos dados disponíveis.

\section{Linguagem}

Todos os projetos apresentam uma linguagem adequada. A análise realizada permitenos concluir que os sete trabalhos utilizam a linguagem específica e termos estatísticos necessários quer para a realização das representações gráficas, quer para a resolução dos TH.

\section{Regras (definições, proposições, procedimentos)}

A análise realizada neste componente leva-nos a concluir que os trabalhos desenvolvidos pelos alunos apresentam representações gráficas ou tabelas de frequência e resoluções dos $\mathrm{TH}$ usando o software $\mathrm{R}$, como era recomendado. Podemos dizer que os indicadores deste componente evidenciam que os estudantes têm noção dos conceitos envolvidos para a obtenção das representações gráficas e dos TH e sabem manipular, ainda que com alguma dificuldade, o software R para a obtenção dos resultados. No entanto, nem todos os trabalhos mostram a concretização das representações gráficas ou TH para todas as questões de investigação estabelecidas com alunos. Quanto à manipulação do software R, os alunos mostraram alguma dificuldade na sua instalação e no seu manuseamento, tendo investido pouco no seu uso e recorrido pouco ao apoio tutorial da professora. 


\section{Relações}

Analisando os trabalhos, podemos afirmar que os alunos mostraram dificuldades nas justificações que teriam que apresentar em função dos resultados obtidos nas resoluções através do software R. Apenas um trabalho (projeto 7) não apresentou dificuldades, enquanto todos os outros apresentaram dificuldades, nomeadamente, na justificação e na explicação dos resultados obtidos na resolução dos vários $\mathrm{TH}$ que foram usados para a concretização dos objetivos propostos. Relativamente ao manuseamento do software $\mathrm{R}$, dos sete trabalhos analisados, quatro não apresentaram dificuldades na aprendizagem e manuseamento e três apresentaram dificuldades, principalmente na resolução dos TH.

A partir da análise dos componentes e indicadores considerados por Godino e seus colaboradores, observa-se que o trabalho proposto sobre as Redes Sociais contempla todos os indicadores a nível da idoneidade epistémica uma vez que, segundo o modelo proposto no EOS, para se obter uma idoneidade epistémica alta devemos ter em conta uma seleção diversificada de situações-problema. Para tal, as situações-problema devem contemplar diversas representações ou meios de expressão, definições, procedimentos, proposições, assim como as respetivas justificações. As tarefas devem proporcionar aos alunos diversas maneiras de abordagem, implicar diversas representações e requerer que os alunos conjeturem, interpretem e justifiquem as soluções.

Em síntese, podemos concluir que o trabalho proposto aos alunos foi ao encontro de todas as indicações do EOS, isto é, foram propostas situações-problema em que se pedia que apresentassem várias formas de representação, que envolviam conceitos e procedimentos e que requeriam a interpretação e justificação de resultados.

\subsection{Análise Da Idoneidade Cognitiva}

Em relação à idoneidade cognitiva, como menciona Godino (2013), a partir das entidades primárias (situações-problema, linguagem, regras, argumentos e relações), as quais caracterizam o modelo epistémico proposto no EOS, deveremos usá-las como guia para elaborar indicadores dos significados pessoais dos alunos. Na Quadro 2 apresentam-se os componentes e indicadores propostos no EOS para a idoneidade cognitiva 
Quadro 2 - Componentes e indicadores da idoneidade cognitiva

\begin{tabular}{|l|l|}
\hline Componentes & Indicadores (referência/uso) \\
\hline $\begin{array}{l}\text { Conhecimentos prévios (têm-se em conta os } \\
\text { mesmos elementos da idoneidade epistémica) }\end{array}$ & $\begin{array}{l}\text { - Os alunos têm os conhecimentos prévios } \\
\text { necessários para o estudo do tema (estudados } \\
\text { anteriormente ou o professor planifica o seu } \\
\text { estudo). } \\
\text { - Os conteúdos pretendidos podem-se alcançar } \\
\text { (têm uma dificuldade manejável) nas suas } \\
\text { diversas componentes. }\end{array}$ \\
\hline Adaptações curriculares às diferenças individuais & $\begin{array}{l}\text { - Incluem-se atividades de ampliação e reforço. } \\
- \text { Promove-se o acesso e sucesso de todos os } \\
\text { alunos. }\end{array}$ \\
\hline $\begin{array}{l}\text { Aprendizagem (têm-se em conta os mesmos } \\
\text { elementos da idoneidade epistémica) }\end{array}$ & $\begin{array}{l}\text { - As diversas formas de avaliação indicam que os } \\
\text { alunos adquiriram os conhecimentos, } \\
\text { compreensões e competências pretendidas. } \\
- \text { Compreensão concetual e proposicional, } \\
\text { competência comunicativa e argumentativa, } \\
\text { fluência procedimental, compreensão situacional } \\
\text { e competência metacognitiva. } \\
- \text { A avaliação tem em conta distintos níveis de } \\
\text { compreensão e de competência. } \\
- \text { Os resultados das avaliações são divulgados e } \\
\text { utilizados para tomar decisões. }\end{array}$ \\
\hline
\end{tabular}

Fonte: Godino, 2013, p. 121

Como no caso da idoneidade epistémica, esta análise vai ser realizada a priori e a posterior, em função dos componentes e indicadores da idoneidade cognitiva que constam da Quadro 2. Os componentes que iremos utilizar para a idoneidade cognitiva vão ser os mesmos da idoneidade epistémica.

\subsubsection{Análise A Priori}

\section{Situações-problema}

S2) Que tipo de situações-problema específicas permite formular o enunciado do trabalho?

Escolher quatro questões de investigação, extraídas do questionário, caracterizar a amostra e indicar que TH poderiam aplicar para as variáveis selecionadas em cada uma delas.

\section{Linguagem}

L1) Os trabalhos apresentam uma linguagem específica: termos; expressões; símbolos e gráficos? 
É expectável que os trabalhos apresentem uma linguagem específica conforme a questão que estejam a resolver.

\section{Regras (definições, proposições, procedimentos)}

R1) Que conceitos específicos se prevê que surjam das práticas matemáticas implementadas? Que conceitos prévios, que se supõem conhecidos, se usam de forma explícita ou implícita?

Nesta componente prevê-se que os alunos tenham conhecimento do tema $\mathrm{TH}$ e dos conceitos que estão envolvidos. Contudo, neste estudo, foram detetadas falhas, ou seja, alguns alunos não conseguiram compreender os conceitos estatísticos e procedimentos envolvidos nos $\mathrm{TH}$, ao não saberem enunciar as hipóteses a partir do contexto de um problema e ao confundirem os significados dos erros tipo I e tipo II. Também constatámos que os conceitos não compreendidos são causadores de erros, destacando-se as dificuldades dos alunos em compreender as noções de hipótese nula e alternativa, a natureza condicional do nível de significância, a interpretação do valor de prova e a lógica de um TH.

R2) Que conceitos específicos se prevê que surjam das práticas matemáticas implementadas na realização dos projetos? Que conceitos prévios, que se supõem conhecidos, se usam de forma explícita ou implícita?

Esta componente abrange a análise e interpretação das informações relativas aos trabalhos de projeto sobre as Redes Sociais, estando implícita a compreensão de conceitos, procedimentos e estratégias matemáticas utilizadas na obtenção dos resultados. Portanto, os alunos teriam de estabelecer que representações e TH deveriam ser utilizados.

\section{Argumentos e relações}

A1) Que tipo de argumentações são necessárias para a resolução das representações gráficas e dos TH usando o software R?

Esperava-se que os alunos justificassem as representações gráficas e tabelas de frequência utilizadas na caracterização da amostra, bem como identificassem os TH a utilizar para cada questão. Além disso, os alunos também deveriam justificar os resultados obtidos através do software R, especificamente a leitura de gráficos, tabelas de frequência e TH. Finalmente, deveriam relacionar os resultados obtidos na resolução dos TH com a tomada de decisão. 


\subsubsection{Análise A Posteriori}

\section{Situações-problema}

Podemos concluir que todos os projetos analisaram a informação fornecida de forma a elaborar estratégias de resolução para as questões de investigação através dos TH, como podemos constatar no plano de trabalho que cada grupo realizou para o seu projeto.

\section{Linguagem}

Todos os trabalhos analisados utilizam a linguagem específica da representação gráfica, tabelas de frequência e termos estatísticos adequados na resolução dos TH. Por exemplo, no caso da formulação das hipóteses: $H_{0}: p_{1}-p_{2}=0 ; H_{1}: p_{1}-p_{2} \neq 0$.

Sintetizando, os projetos evidenciam a leitura e a interpretação de dados em diferentes linguagens.

\section{Regras (definições, proposições, procedimentos)}

Alguns projetos não apresentam nenhum gráfico de barras ou histograma para os dados disponíveis (projeto 2, projeto 3 e projeto 5).

Relativamente às representações gráficas adequadas para a caraterização da amostra, todos os grupos apresentaram pelo menos um tipo de representação adequada (gráfico de barras, histograma, tabela de frequências), identificaram os TH a utilizar para cada uma das questões de investigação escolhidas e são apresentadas as representações gráficas (gráficos de barra, histogramas, tabelas de frequência) e os TH através do software R.

Para além disso, nem todos grupos conseguiram compreender os conceitos estatísticos e procedimentos envolvidos nos TH uma vez que não souberam aplicar os TH para algumas das questões de investigação que selecionaram (projeto 1, projeto2 e projeto 5). Apenas o projeto 6 cumpriu os indicadores estabelecidos para a caracterização da amostra e para a resolução dos $\mathrm{TH}$, apresentando para todas as questões de investigação: a construção das representações gráficas (gráficos de barra e circulares, tabelas de frequência) e a respetiva interpretação; e a resolução dos TH e a sua interpretação relativamente aos resultados obtidos.

Podemos, assim, concluir que os erros detetados nesta análise são semelhantes àqueles que se verificaram na análise a priori.

\section{Argumentos e relações}

Quanto à interpretação dos resultados obtidos nas representações gráficas, observaramse falhas nos projetos 2, 3 e 5, porque não apresentaram nenhuma conclusão. Relativamente à 
interpretação dos resultados obtidos para os $\mathrm{TH}$, era esperado que fossem tiradas conclusões em função da tomada de decisão de rejeitar ou não a hipótese nula, o que não foi feito. Dos sete projetos, três (projetos 4, 6 e 7) extraíram essa conclusão para todas as questões, enquanto os outros projetos tiraram as conclusões através do intervalo de confiança (IC), da análise da tabela de frequências, da proporção ou da média obtida na resolução através do software R.

No entanto, na apresentação oral, os grupos foram explicando que representações gráficas realizaram e que conclusões tiraram nas várias questões que escolheram. Quanto aos $\mathrm{TH}$, alguns grupos conseguiram tirar ilações através dos resultados obtidos para rejeitar ou não a hipóteses nula, o que no relatório não estava explícito (projetos 2, 4 e 5).

Podemos então concluir que a apresentação oral do trabalho complementou e até esclareceu a forma como os alunos raciocinaram estatisticamente (projetos 2, 5 e 7).

Tal como se verificou na análise a priori, nesta análise os alunos também não apresentaram justificações.

Sintetizando, da análise realizada aos sete trabalhos de projeto sobre as Redes Sociais, a nível cognitivo, pode-se depreender que nem todos os indicadores foram contemplados nos sete trabalhos de projeto, verificando-se que os projetos 1, 2, 3 e 5 falham no indicador Regras (definições, proposições, procedimentos) e os projetos 1, 2 e 5 falham no indicador Argumentos e relações.

\subsection{Análise Da Idoneidade Mediacional}

Segundo Godino (2011), é importante considerar como elementos mediacionais a determinação das condições ambientais da sala de aula, a relação professor/aluno e o tempo destinado ao ensino e à aprendizagem dos conceitos. Na Quadro 3 indicam-se os componentes e indicadores da idoneidade mediacional propostos pelo EOS.

Quadro 3 - Componentes e indicadores da idoneidade mediacional

\begin{tabular}{|c|c|}
\hline Componentes & Indicadores (referência/uso) \\
\hline $\begin{array}{l}\text { Recursos materiais } \\
\text { (manipulativos, calculadoras, } \\
\text { computadores) }\end{array}$ & $\begin{array}{l}\text { - Usam-se materiais manipulativos e informáticos que permitam } \\
\text { introduzir situações pertinentes, linguagens, procedimentos e } \\
\text { argumentações adaptadas ao conhecimento pretendido. } \\
\text { - As definições e propriedades são contextualizadas e motivadoras, } \\
\text { usando situações e modelos concretos e visualizações. }\end{array}$ \\
\hline $\begin{array}{l}\text { Número de alunos, horário e } \\
\text { condições em sala de aula }\end{array}$ & $\begin{array}{l}\text { - O número e a distribuição dos alunos permite levar a cabo o } \\
\text { ensino pretendido. }\end{array}$ \\
\hline
\end{tabular}




\begin{tabular}{|l|l|}
\hline & $\begin{array}{l}\text { - O horário do curso é apropriado (por exemplo, não se dão todas } \\
\text { as aulas à última hora). } \\
\text { - A aula e a distribuição dos alunos é adequada para o } \\
\text { desenvolvimento do processo de instrução pretendido. }\end{array}$ \\
\hline $\begin{array}{l}\text { Tempo (de ensino } \\
\text { coletivo/tutorial; tempo de } \\
\text { aprendizagem) }\end{array}$ & $\begin{array}{l}\text { - O tempo (presencial e não presencial) é suficiente para o ensino } \\
\text { pretendido. } \\
\text { - Dedica-se tempo suficiente aos conteúdos mais importantes do } \\
\text { tema. } \\
\text { - Dedica-se tempo suficiente aos conteúdos que apresentam maior } \\
\text { dificuldade de compreensão. }\end{array}$ \\
\hline
\end{tabular}

Fonte: Godino, 2013, p. 125

A análise a priori e a posteriori que iremos apresentar seguidamente realiza-se tendo em conta os componentes e indicadores antes referidos e enfatizando o uso do computador e do software R.

\subsubsection{Análise A Priori}

\section{Recursos didáticos}

R1) Que recursos didáticos se podem aplicar neste trabalho de projeto?

Apontamento da unidade curricular, computador e software R.

R2) De que forma se podem utilizar os recursos tecnológicos?

Utilizar adequadamente os recursos tecnológicos como instrumento de produção de resultados.

Utilizar o software R para responder às questões de investigação (representações gráficas, tabelas de frequência e TH).

\section{Número de alunos, horário e condições em sala de aula}

C1) O número de alunos permite a realização deste trabalho de projeto em sala de aula?

Os alunos foram distribuídos por sete grupos, perfazendo um total de 31 alunos.

Cada grupo continha quatro ou cinco alunos.

\section{Tempo}

T1) O tempo dedicado à aprendizagem do conceito TH foi suficiente?

$\mathrm{O}$ tempo dedicado à aprendizagem teórica do conceito $\mathrm{TH}$ foi de duas horas letivas, duas aulas teóricas de uma hora cada uma.

T2) O tempo dedicado ao projeto (presencial e não presencial) foi suficiente para a sua realização? 
O tempo presencial perfez um total de seis horas.

O tempo tutorial (extra-aulas) perfez um total de quatro horas.

\subsubsection{Análise $A$ Posteriori}

\section{Recursos didáticos}

Analisando os sete trabalhos de projeto verificamos que em todos eles foi usado o software $\mathrm{R}$, conforme tinha sido pedido nas recomendações para a realização do trabalho. Contudo, os grupos apresentaram dificuldades na instalação e na aprendizagem do software R, que se repercutiram na realização dos TH. Essas dificuldades foram detetadas nos projetos 1, 4 e 5 .

\section{Número de alunos, horário e condições em sala de aula}

Os alunos foram distribuídos por sete grupos, dos quais três eram constituídos por cinco alunos e quatro por quatro alunos, perfazendo um total de 31 alunos, o que se revelou um número aceitável de alunos, permitindo à professora interagir com todos eles.

O projeto foi realizado, fundamentalmente, em sala de aula. Por outro lado, o facto de os alunos usarem os seus computadores pessoais e de o software utilizado ser de livre acesso, permitiu a cada grupo instalar o software R no seu computador e, a partir desse momento, começar a desenvolver o seu projeto.

\section{Tempo}

Fazendo uma análise global ao tempo disponibilizado para o estudo dos $\mathrm{TH}$, podemos concluir que as aulas teóricas para a apresentação dos conteúdos se revelaram suficientes; no entanto, as aulas teórico-práticas para a realização do projeto não foram suficientes, tendo os alunos de finalizar o projeto fora das aulas. No questionário sobre "Perceções dos alunos sobre o trabalho de projeto", relativamente à questão sobre se o tempo foi adequado para a realização das várias fases do projeto sobre as Redes Sociais, 22,2\% dos alunos referiram que com o trabalho que tinham de realizar noutra UC (em paralelo com o das Redes Sociais) não foi possível dedicar o tempo necessário para a realização do projeto. Já $51,9 \%$ afirmou que o tempo foi devidamente dividido e aplicado para a resolução das várias fases do projeto.

O tempo tutorial, disponibilizado fora do horário das aulas, revelou-se suficiente uma vez que dos sete grupos que realizaram o projeto apenas um apareceu no horário disponibilizado para esse efeito. 
Concluindo, podemos afirmar que a utilização do software $\mathrm{R}$ para a realização do trabalho de projeto foi pertinente. Porém, a idoneidade do processo de estudo foi afetada porque os alunos, além de demonstrarem dificuldades na sua instalação e no seu manuseamento, apresentaram também dificuldades na sua aprendizagem, que se refletiram na realização dos TH previstos para responder às questões de investigação. A conclusão sobre a dificuldade na instalação e manuseamento do software $\mathrm{R}$ foi retirada da análise realizada ao questionário "Perceções dos alunos sobre o trabalho de projeto", em que 51,9\% dos alunos inquiridos afirmaram que sentiram "Algumas dificuldades iniciais por ser um programa com o qual não estávamos habituados a trabalhar", segundo alguns elementos dos grupos dos projetos analisados.

Apesar dessas dificuldades, os alunos mostraram interesse na utilização do software R, uma vez que este recurso evita ter que realizar os cálculos à mão, construir tabelas e resolver TH analiticamente.

\section{Conclusões}

Após a análise realizada aos sete projetos, de acordo com as dimensões da idoneidade epistémica, cognitiva e mediacional, podemos concluir que ela foi útil para extrair ilações da forma como o projeto foi implementado. No caso da idoneidade epistémica, considera-se que o processo de estudo realizado revelou um nível de idoneidade elevado, uma vez que foram observados todos os indicadores desta dimensão de idoneidade.

Em relação à idoneidade cognitiva, podemos afirmar que existiram algumas deficiências por parte dos alunos, no que diz respeito à análise e interpretação dos resultados. Portanto, através dos indicadores adotados, fica-se com a noção de que deveremos modificar a forma de lecionação teórica dos conceitos sobre TH.

Por último, no caso da idoneidade mediacional, os indicadores conduzem à recomendação de que se dê mais tempo para a aprendizagem do software $\mathrm{R}$ antes de apresentar um projeto que envolva a sua utilização.

Portanto, a análise produzida sobre a realização de um projeto para a aprendizagem de conceitos estatísticos, envolvendo dados reais e do interesse dos estudantes (Fernandes et al., 2007), permitiu perceber que a metodologia trabalho de projeto apresentou como ponto forte a idoneidade epistémica. 
Por fim, de acordo com o diagrama que explicita os graus de idoneidade das diferentes dimensões, proposto por Godino, Batanero e Font (2008) e já exposto na secção 2.1, a partir da análise produzida, podemos afirmar que a idoneidade epistémica é considerada alta e as idoneidades cognitiva e mediacional são consideradas médias uma vez que nem todos os indicadores foram satisfeitos.

Os aspetos menos conseguidos no presente estudo sugerem que é importante continuar a investigação sobre o raciocínio inferencial dos alunos, nomeadamente nos testes de hipóteses, de forma a determinar um melhor ensino para assegurar uma adequada idoneidade cognitiva. Como o raciocínio inferencial não pode ser desenvolvido num curto espaço de tempo, seria importante começar a introduzi-lo de forma informal desde o ensino secundário (Harradine, Batanero \& Rossman, 2011).

\section{Agradecimentos}

Este trabalho é financiado pelo CIEd - Centro de Investigação em Educação, UID/CED/01661/, Instituto de Educação, Universidade do Minho, através de fundos nacionais da FCT/MCTES-PT; EDU2016-74848-P (AEI, FEDER).

\section{Referências}

Ara, A., \& Musetti, A. (2001). Avaliação de uma nova metodologia no ensino da Estatística para o curso de Engenharia. In Anais do XXIX Congresso Brasileiro de Ensino de Engenharia (COBENGE 2001, pp. 245-250). Rio Grande do Sul: Pontifícia Universidade Católica do Rio Grande do Sul, Faculdade de Engenharia.

Batanero, C. (2001). Didáctica de la Estadística. Granada: Departamento de Didáctica de la Matemática, Universidad de Granada.

Fernandes, J. A., Carvalho, C., \& Ribeiro, S. A. (2007). Caracterização e implementação de tarefas de Estatística: um exemplo no 7. $^{\circ}$ ano de escolaridade. Zetetiké, 15(28), 27-61.

Fernandes, J. A., Júnior, A. P. O., \& Vasconcelos, A. P. (2013). Caracterização, implementação e avaliação de uma estratégia de ensino de estatística no $7 .^{\circ}$ ano. Perspectivas da Educação Matemática, 6(11), 93-109.

Fischbein, E. (1975). The intuitive sources of probabilistic thinking in children. Dordrecht: D. Reidel. 
Godino, J. D. (2011). Indicadores de la idoneidad didáctica de procesos de enseñanza y aprendizaje de las matemáticas. In Anais da XIII Conferência Interamericana de Educação Matemática, Recife, Brasil, 26-30 junho.

Godino, J. D. (2013). Indicadores de idoneidad didáctica de procesos de enseñanza y aprendizaje de las matemáticas. Cuadernos de Investigación y Formación en Educación Matemática, 11, 111-132.

Godino, J. D. Batanero, C., \& Font, V. (2007). The onto-semiotic approach to research in mathematics education. ZDM, The International Journal on Mathematics Education, 39(12), 127-135.

Godino, J. D., Batanero, C., \& Font, V. (2008). Um enfoque ontossemiótico do conhecimento e a instrução matemática. Revista de Ensino de Ciências e Matemática, 10(2), 1-32.

Godino, J. D., Contreras, A., \& Font, V. (2006). Análisis de procesos de instrucción basado en el enfoque ontológico-semiótico de la cognición matemática. Recherches en Didactiques des Mathématiques, 26(1), 39-88.

Godino, J. D., Wilhelmi, M. R., \& Bencomo. D. (2005). Suitability criteria for a mathematical instruction process. A teaching experience with the function notion. Mediterranean Journal for Research in Mathematics Education, 4(2), 1-26.

Gonçalves, G., Fernandes, J. A., \& Nascimento, M. (2015). Compreensão dos testes de hipóteses por alunos do curso de Engenharia Informática. In J. M. Contreras, C. Batanero, J. D. Godino, G. R. Cañadas, P. Arteaga, E. Molina, M.M. Gea, \& M. M. López (Eds.), Didáctica de la Estadística, Probabilidad y Combinatoria, 2 (pp. 171-178). Granada: Universidade de Granada.

Gonçalves, G., Fernandes, J. A., \& Nascimento, M. M. (2014). Conflitos semióticos na resolução de uma tarefa de testes de hipóteses de alunos do ensino superior politécnico. Indagatio Didatica, 6(5), 37-56.

Harradine, A., Batanero, C., \& Rossman, A. (2011). Students and teachers' knowledge of sampling and inference. In C. Batanero, G. Burrill, \& C. Reading (Eds.), Teaching statistics in school mathematics: Challenges for teaching and teacher education. A joint ICMI/IASE study (pp. 235- 246). New York: Springer.

Petocz, P., \& Reid, A. (2007). Learning and assessment in statistics. In B. Phillips, \& L. Weldon (Eds.), The Proceedings of the ISI/IASE Satellite on Assessing Student Learning in Statistics. Voorburg: International Statistical Institut

Submetido em: 18/05/2018 Aceito em: 06/09/2019 